\title{
Assessing Geographic Conchological Variations of the Different Banding Patterns in the Invasive Giant African Land Snail Achatina fulica From the Philippines
}

\author{
Jade Marie M. Sobrepeña and Cesar G. Demayo
}

\begin{abstract}
Population of the invasive giant African snail Achatina fulica in the Philippines show conspicuous shell variations, which involve banding pattern, colour, size, and shape. Generally, shell shape and colour of land snails have been related to environmental factors. Therefore, the objective of this study is to determine and assess shape variations across population of geographically isolated shells with different banding patterns. Morphological analysis was performed on a total of 1309 matured shells from 15 different geographical locations across the Philippine island. Relative warp analysis revealed variation shell shape which could be slender-shaped or round-shaped. A variation in spire-whorl length coupled with aperture size was also observed. Canonical variance analysis scatter plot presented overlapping of populations from different geographical locations. Though there were no directly observable differences on the consensus shape superimposition of each geographically isolated population, results of multivariate analysis, Kruskal-Wallis test, and cluster analysis showed significant relationship of shell morphology of different banding patterns to geographical locations. However, the scattered distribution and short distance variation suggested a higher intrapopulation variation rather than interpopulation. Phenotypic plasticity, common in land snails, could be another explication for the observed intrapopulation conchological variations and that differentiation could also be due to multitude reactions to endogenous and exogenous factors.
\end{abstract}

Index Terms-Achatina fulica, banding pattern, geometric morphometrics, invasive snail, morphology, shell shape.

\section{INTRODUCTION}

Considered as one of the " 100 world's worst invasive species" [1]-[3] and the most ecologically damaging land snails [4], [5], the giant African land snail Achatina fulica is globally distributed in the places where the snail species multiply rapidly and may caused significant economic loose [6]. The broad distribution of the snails could not only be charged to active expansion from established populations but also to the repeated transportation opportunities provided by human [2], [7]. Together, local population expansion, and purposely and accidently introduction of A. fulica have contributed to a rapid geographical range expansion of this

Manuscript received February 23, 2014; revised April 25, 2014. This work was supported in part by the Department of Science and Technology Accelerated Science and Technology Human Resource Development Program (DOST-ASTHRDP).

The authors are with the Department of Biological Sciences, College of Arts and Sciences, MSU - Iligan Institute of Technology, Iligan City, Philippines (e-mail:_ jademariesobrepena@gmail.com, cgdemayo@gmail.com). invasive species [2], [8]-[10].

The evolutionary processes shaping the phenotypic variation among and within natural populations of land snails have been a focus of research interest since the early year of 1990s [11]. Studies that centered on the dispersal, distribution, and biology of the A. fulica have been performed since 1950s [6], [12]. However, information about the known factors affecting the snail biology, especially invasive species, is still lacking [13]. Shells of land snails provide relevant morphometric data used for taxonomy and phylogenetic inference as well as population biology [14], [15]. Since a strong population structure is most likely found in species with restricted vagility, the usual slow pace (inferring poor dispersal potential) of land snails, therefore, makes these species suited subjects for studying differentiation in space and time or on the issue of phenotypic evolution [11], [16]. Being an invasive species makes Achatina fulica an even more interesting organism for studying conchological variations since admixture of populations is restricted and the snails are able to adapt to different series of endogenous and exogenous factors. It is known that from the country of origin to its introduction to the different areas of the world, including the Philippines, phenetic variations within and among populations of A. fulica have been observed and this connotes that this species may have diverged from the native population [17]. A. fulica in the Philippines shows conspicuous shell variations, which involve banding pattern, colour, size, and shape. Generally, shell shape and colour of land snails have been related to certain environmental conditions [6]. In the Philippines, it is notable morphological variation of shell shape of geographically isolated snails [17] and also a significant correlation of shell shape and banding pattern categorization [13] of A. fulica was observed using geometric morphometric analysis. Geometric morphometric methods have further enabled the partitioning of shape and size components which preserve the main geometric properties of the specimen while generating visual representation and determining shape variables that can be statistically analyzed [18].

Thus, the objective of this study is to determine and assess the relationship between shell shape of different banding patterns and geographical location to further understand the nature of conchological variation in Achatina fulica. The variations among shell population of different banding patterns were quantitatively described by applying the tools of geometric morphometrics (GM) specifically landmarks-based and relative warp analysis. 


\section{MATERIALS AND METHODS}

\section{A. Sampling Sites}

Snail samples were collected from 15 different provinces across the Philippines: Cagayan (Tuguegarao City), Pangasinan (Calasiao), Quezon (Lucena City), and Rizal (Antipolo City) in Luzon; Bohol (Agapi, Ondol, and Kinogitan) and Southern Leyte (Sogod) in Visayas; and Compostela Valley (Las Arenas), Davao del Norte (New Corella and Panabo City), Davao del Sur (Emily Holmes, Riverside, Nova Tierra Village, Mandug in Davao City and Padada), Lanao del Norte (MSU-IIT campus and Mimbalot Falls, Iligan City), Lanao del Sur (Marawi City), Misamis Occidental (Cagayan de Oro City), South Cotabato (General Santos City), and Zamboanga Sibugay (Ipil). Fig. 1 shows the map of the Philippines plotted with the corresponding sampling sites.

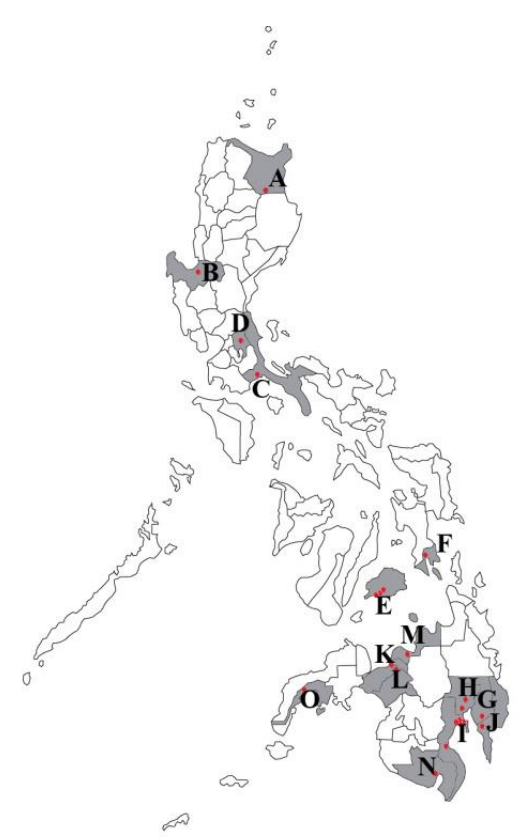

Fig. 1. Map of the Philippines showing different geographical locations of the sampling sites. Colored regions correspond to the 15 provinces and the red dots to the locations of the different sampling sites. Legend : Cagayan (A), Pangasinan (B), Quezon (C), Rizal (D), Bohol (E), Southern Leyte (F), Compostela Valley (G), Davao del Norte (H, Davao del Sur (I), Davao Oriental (J), Lanao del Norte (K), Lanao del Sur (L), Misamis Oriental (M), South Cotabato $(\mathrm{N})$, and Zamboanga Sibugay $(\mathrm{O})$.

\section{B. Banding Pattern Categorization, Imaging, Organizing and Digitalization}

A total of 1309 mature shells were collected from the different sampling sites and were categorized into 14 body whorl banding pattern described by [13].

For imaging, shells were positioned in such a way that the columellar is at $90^{\circ}$ of the $\mathrm{x}$-axis in the aperture view and in the orientation in which the apex is visible. The digital images of the shells were then captured using a high resolution digital single-lens reflex (DSLR) camera with manual focus setting mounted on a tripod to maintain the distance for all samples, and to ascertain uniformity and minimize errors.

Shell samples were grouped according to the banding pattern categorization under different geographical locations. Triplicates of the images were made to insure reliable data for analysis. The images of the grouped samples were digitized using tpsUtil [19] and saved as thin-plate splines (TPS) files. TPS files were further pooled by geographical locations.

\section{Landmark selection and Landmarking}

A total of 50 landmarks defined by [17] were used to summarize the shape of the shell (Fig. 2). Landmarks and pseudolandmark points were assigned to prominent features in the shells of A. fulica. Landmarks were designated to homologous structures found in the shell to ensure consistency in number from shell to shell.

TPS files of the pooled digital images were then subjected to landmark acquisition using tpsDig2.12 [20] program to facilitate the establishment of the " $x$ " and " $y$ " coordinates of the landmarks. Links and sliders were also generated to enhance the image of the specimens in the landmark-based analysis.

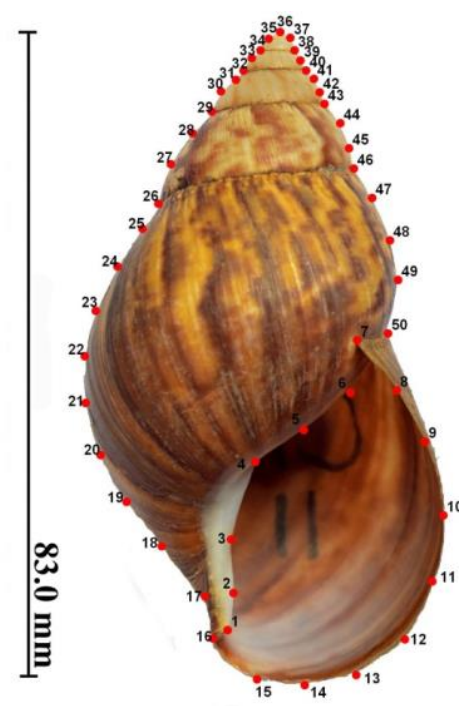

Fig. 2. Designated landmarks and pseudolandmarks on the shell of A. fulica.

\section{Landmark-Based and Statistical Analysis}

Relative warp (RW) analysis using tpsRelw [21] was used to generate information of the variation in the local shape. This landmark-based analysis involved fitting and interpolation function to homologous landmarks for each specimen in a sample. Significant RW scores were then used to create histogram and box-and-whiskers plot using the paleontological Statistic (PAST) software [22]. The first and second RW scores (most significant warp scores) were then subjected to Multivariate Analysis of Variance (MANOVA) and Canonical Variance Analysis (CVA). The histogram, box-and-whiskers, and scatter plots were used to visualize where the data were centered or distributed over range of variables, whereas MANOVA was used to determine the significance of the correlation of shell shape and geographical locations. TPS files were imported to PAST software for the plotting of the XY graph and generation of the expansion map after a general Procrustes analysis. Consensus images of each population of $A$. fulica from different sampling sites were superimposed for easier visualization of observable variation on shell shapes.

Pooled different geographical locations were used for all succeeding statistical analysis. Kruskal-Wallis test, a nonparametric test used to compare independent groups of sample data and to determine significance of difference [23], 
was performed. The most significant RW scores were used for Kruskal-Wallis test to compare and determine the difference (at 0.05 level of significance) in the shell shape variation of snail populations of different geographical locations. Centroid data obtained from tpsRelw [22] people population of A. fulica from different sampling sites were used in Cluster analysis; this helped separate multivariate data into a series of hierarchically related sets [24]. All statistical analyses were performed using PAST software.

\section{RESULTS AND DISCUSSIONS}

The results of the relative warp (RW) analysis for the shell shape of Achatina fulica showed four general shape morphologies which were consistent with the results of related studies [13], [17]: elongated spire with narrow body whorl and narrow aperture, elongated spire with narrow body whorl and rounded aperture, short spire with wide body whorl and narrow aperture, and short spire with wide body whorl and rounded aperture. Results of the relative warps visualizing the mean shapes and the distribution of the shell morphologies are shown in Fig. 3 and the description of the different RW shapes is presented in Table I.

Results were consistent with the study of [13] on the assessment of banding pattern and shell shape relationship. Conchological variations include shell shapes (slender-shaped or round-shaped), spire-body whorl length aspect (longer spire-narrow body whorl or short spire-wider body whorl corresponding to the shell shape, respectively), aperture length-wide aspect, aperture margin shape, and the shell orientation (leaning towards the right or left direction). The first relative warp (RW1) explained the approximately $50-60 \%$ of the shape variations in the giant African snail. RW1 showed the variation in shell shape and spire-whorl length aspect with the variation in shell width, which was due to the relationship of body length and aperture size. Wide shell morphology could be: wide body whorl with narrow aperture size or narrow body whorl with wider aperture opening. The second relative warp (RW2) approximately $20-30 \%$ of the variation within population, illustrated in this warp the variation in shell shape and spire-whorl length aspect with the difference in aperture outer margin shape, which varied from having a wider lower portion to a more concave shaped upper margin giving a different shape to the aperture outer lip. The third relative warp (RW3) described the variation in aperture shape with the variation in landmark (LM) 3 and 4, where the variation in LM points could give a more pronounced inner lip shape of the aperture. The forth relative warp (RW4) showed the variation in shell orientation with slight difference in shell width and aperture size, and variation in LM 17 and 18, where variation could cause a more concave body whorl shape. And lastly, the fifth relative warp (RW5) demonstrated solely the variation in shell orientation. The inconsistency of significant warps of the different geographical locations may suggest the degree of intrapopulation variation.

Moreover, the histogram and the box-and-whiskers plots of the significant warps displayed a multimodal distribution of variation in shells with different banding patterns within geographically isolated populations of snails. Distribution of mean shell shapes was observed to be scattered in geographical locations. This finding also implied high variation on the intrapopulation level.

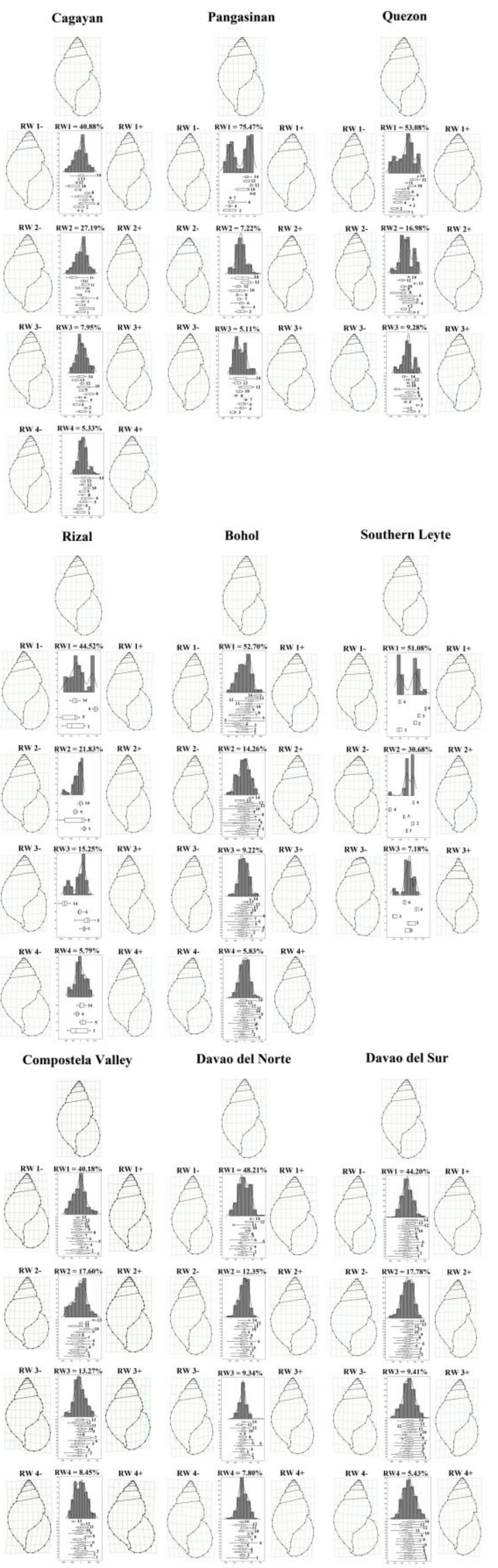

Fig. 3. Summary of the landmark based geometric morphometric analysis showing the consensus morphology (uppermost pannel) and the variation in shape of the shells of Achatina fulica from different geographical locations explained by each of the significant relative warps. 
TABLE I: VARIABILITY IN THE SHELLS OF ACHATINA FULICA SHELl FROM DifFERENT GEOGRAPHICAL LOCATIONS AS EXPLAINED BY THE SigNIFICANT RELATIVE WARP

\begin{tabular}{|c|c|}
\hline RW & $\begin{array}{ll}\text { Cagayan } \\
\end{array}$ \\
\hline 1 & $\begin{array}{l}\text { - Variation in spire-body whorl length aspect; higher spire and length and shorter body whorl length (+), shorter spire length and } \\
\text { longer body whorl length (-). } \\
\text { - Slight difference in shell length and width; higher length and wider width in (-). } \\
\text { - Variation in aperture margin size; higher length and width in (-). }\end{array}$ \\
\hline 2 & $\begin{array}{l}\text { - Variation in shell shape; slender (-) and rounder (+) } \\
\text { - Variation in shell width; wider body width (+) and with wider aperture width, slender shell shape with narrower shell width (-). }\end{array}$ \\
\hline 3 & $\begin{array}{l}\text { - Slight difference in shell shape orientation; (-) leaning to the right and (+) leaning to the left } \\
\text { - Variation in the size and shape of aperture margin }\end{array}$ \\
\hline 4 & $\begin{array}{l}\text { - Variation in spire- whorl length aspect; higher spire height in }(+) \\
\text { - Slight difference in shell width and very minimal difference in aperture width }\end{array}$ \\
\hline RW & Pangasinan \\
\hline 1 & $\begin{array}{l}\text { - Variation in the shell shape; slender (-) and rounder (+) shaped. } \\
\text { - Differences in spire-body whorl length aspect; slender shell shape (-) have higher spire length with shorter body whorl length, } \\
\text { while the rounder shell shape is the opposite (+). } \\
\text { - Difference in shell width; wider (+) and narrower in (-). } \\
\text { - Approximately the same aperture margin width. Difference in aperture margin length; longer in }(+) \text { and shorter in (-). }\end{array}$ \\
\hline 2 & $\begin{array}{l}\text { - Variation in spire-whorl length aspect; higher spire-shorter body whorl length in }(+) \text {, shorter spire with longer body whorl length } \\
\text { (-). } \\
\text { - Difference in aperture outer margin shape; wider opening in the upper part margin }(+) \text { and or elongated in the lower part margin. }\end{array}$ \\
\hline 3 & $\begin{array}{l}\text { - Variation in the aperture margin shape; rounder shape with wider width and shorter length of the aperture }(+) \text {, and slender shaped } \\
\text { with higher length and narrow width of the aperture. }\end{array}$ \\
\hline RW & Quezon \\
\hline 1 & $\begin{array}{l}\text { - Variation in the shell shape; slender (-) and rounder (+) } \\
\text { - Differences in spire-body whorl length aspect; slender shell shape (-) have higher spire length with shorter body whorl length, } \\
\text { while the rounder shell shape is the opposite }(+) \text {. } \\
\text { - Difference in aperture margin length; longer in }(+)\end{array}$ \\
\hline 2 & $\begin{array}{l}\text { - Variation in aperture shape; slender (-) and rounder (+) shape. Longer aperture length in (-). } \\
\text { - Difference in shell width; wider in (+). }\end{array}$ \\
\hline 3 & $\begin{array}{l}\text { - Variation in spire length with longer spire in (-) and shorter in (+). } \\
\text { - Approximately the same aperture margin width. Difference in aperture margin length; longer in }(+) \text { and shorter in (-). } \\
\text { - Variation in LM 3\& 4; more pronounce inner aperture margin (-). }\end{array}$ \\
\hline RW & Rizal \\
\hline 1 & $\begin{array}{l}\text { - Variation in spire \& shell length; longer spire \& shell length in }(+) . \\
\text { - Difference in aperture margin shape; longer length with narrow width (-) and wider width with shorter length }(+) .\end{array}$ \\
\hline 2 & - Difference in aperture length-width aspect; longer length and smaller width aperture (+), and shorter length wider aperture (-). \\
\hline 3 & $\begin{array}{l}\text { - Variation in the orientation; leaning to the left }(+) \& \text { to the right }(-) \text {. } \\
\text { - Difference in aperture size; slender shape (-) have longer aperture length with smaller width and rounder shape with elongation } \\
\text { on the lower part of the outer margin have shorter length with wider aperture width. }\end{array}$ \\
\hline 4 & - Variation in orientation; leaning to the left $(+) \&$ to the right $(-)$ \\
\hline RW & Bohol \\
\hline 1 & $\begin{array}{l}\text { - Variation in the shell shape; slender (-) and rounder (+) shaped. } \\
\text { - Differences in spire-body whorl length aspect; slender shell shape (-) have higher spire length with shorter body whorl length, } \\
\text { while the rounder shell shape (+) is the opposite. } \\
\text { - Difference in shell width; wider width in rounder shell (+) and narrower body width in slender shell (-). } \\
\text { - Difference in aperture size; higher length and width in (+) }\end{array}$ \\
\hline 2 & $\begin{array}{l}\text { - Variation in the shell shape; slender or more elongated (-) and rounder (+) shaped. } \\
\text { - Differences in spire-body whorl length aspect; slender shell shape }(-) \text { have shorter spire length with longer body whorl length, } \\
\text { while rounder shell shape }(+) \text { has longer and wider spire with shorter wider body whorl. } \\
\text { - Difference in aperture size and shape; longer aperture length }(-) \text { and wider opening or width with shorter length }(+) \text {. }\end{array}$ \\
\hline 3 & $\begin{array}{l}\text { - Variations in shell width; slender shell shape (-) have lower shell width value while rounder shape (+) has wider shell width. } \\
\text { - Differences in aperture size; slender shape (-) have longer aperture length with smaller width and rounder shape with elongation } \\
\text { on the lower part of the outer margin have shorter length with wider aperture width. } \\
\text { - Variation in LM 3\& 4; more pronounce inner aperture margin (-). }\end{array}$ \\
\hline 4 & $\begin{array}{l}\text { - Variation in shell shape orientation; leaning to the right }(-) \text { and leaning towards the left }(+) \text {. } \\
\text { - Difference in aperture size and shape; slender and smaller aperture }(+) \text {, rounder and bigger aperture }(-) .\end{array}$ \\
\hline RW & Southern Leyte \\
\hline 1 & $\begin{array}{l}\text { - Variation in the shell shape; very slender (-) and rounder (+). } \\
\text { - Differences in spire-body whorl length aspect; slender shell shape (-) have higher spire length with shorter body whorl length, } \\
\text { while the rounder shell shape }(+) \text { is the opposite. } \\
\text { - Difference in shell width; wide (+) and narrow (-). }\end{array}$ \\
\hline 2 & $\begin{array}{l}\text { - Variation in spire- whorl length aspect; longer spire with shorter body whorl (-) and shorter spire with loner body whorl length (+). } \\
\text { - Difference in LM 22, 23, 24, 47, } 48 \text { \& 49; concave body whorl (-). } \\
\text { - Difference in aperture size; length and width higher in (-) }\end{array}$ \\
\hline 3 & $\begin{array}{l}\text { - Variation in spire shape; very narrow spire with a pointed apex }(+) \text { and shorter spire with higher width and a blunt shaped apex } \\
(-) \text {. }\end{array}$ \\
\hline RW & Compostela Valley \\
\hline 1 & $\begin{array}{l}\text { - Variation in spire-body whorl length aspect; longer spire with shorter body whorl length }(+) \text { and shorter spire with loner body } \\
\text { whorl length (-). } \\
\text { - Difference in body or shell width, wider shell size in (-) than }(+) \text {. }\end{array}$ \\
\hline 2 & $\begin{array}{l}\text { - Slight variation in spire-body whorl length aspect which is of the same sections in RW } 1 . \\
\text { - Difference in body or shell width, wider shell size in (-) than (+). } \\
\text { - Variation in the aperture size; shorter and wider aperture corresponding to a rounder shaped margin (-), and longer- narrower }\end{array}$ \\
\hline
\end{tabular}


aperture corresponding to a slender or elongated margin shape (+)

- Variation in shell orientation; leaning to the right (+) and leaning to the left (-).

lower part of the margin (-).

- Variation in shell orientation; leaning to the right (+) and leaning to the left (-).

4 - Difference in aperture outer margin shape which is of the opposite component of RW3; wider in the upper part with a longer aperture length (-) and more elongated in the lower part of the margin (+).

- Variation in shell shape; slender shaped (-) and rounder shaped (+) shells.

1 - Difference in spire-body whorl length aspect; higher spire-shorter body whorl (-) and shorter spire-longer body whorl (+).

- Difference in the aperture length and width; bigger aperture in $(+)$ than $(-)$ with a lower length and width of the aperture.

- Variation in shell shape; slender shaped (-) and rounder shaped (+) shells.

$2 \quad$-Difference in spire-body whorl length aspect; higher spire-shorter body whorl (+) and shorter spire-longer body whorl (-).

- Difference in the aperture length and width; bigger aperture in (-) than (+) with a lower length and width of the aperture.

- Variation in shell orientation; (+) is leaning towards the left.

3 - Slightly different in aperture outer margin shape; larger or wider in the lower part of the margin $(+)$

$4-$ Variation in shell orientation; (+) is leaning towards the left.

- Difference in aperture outer margin shape; larger or wider in the lower part of the margin (-).

\section{RW Davao del Sur}

- Variation in shell shape; slender (-) and rounder (+).

- Difference in spire-body whorl length aspect; shorter spire-longer body whorl length (-) and longer spire-shorter body whorl.

- Minimal difference in shell length. Difference in shell width; wider in round shaped shell (+).

- Difference in aperture size; larger aperture opening in $+\mathrm{RW}$.

- Variation in shell shape; slender (+) and rounder (-).

- Difference in spire length; higher in (-).

- Difference in body or shell width; wider shell (-).

- Difference in aperture outer margin shape; more concave shape (-) and elongated in the lower part of the margin (+).

- Variation in orientation; leaning to the left (-) and to the right (+).

- Variation in spire length-width aspect; shorter wider spire (+) and longer narrower spire (-).

3 - Difference in aperture size; longer narrower opening, a slender shape aperture $(+)$, and shorter wider opening with larger lower part, a rounder shape aperture (-).

- Variation in spire orientation; leaning to the left (+) and leaning towards the right (-).

4 - Difference in aperture outer margin shape; longer narrow opening made a slender shape aperture $(+)$ and shorter wider opening with larger lower part corresponds to a rounder shape aperture (-)

- Variation in shell orientation; leaning to the left (+), to the right (-).

1 - Difference in spire-body whorl length aspect; longer spire - shorter body whorl length (+) and shorter spire - longer body whorl $(+)$.

- Difference in aperture size; longer and wider in (+).

- Variation in spire orientation; leaning to the left (-) and leanig towards the right (+).

- Slight difference in shell length; longer shell (+).

- Difference in LM 17 and 18 making a pronounce body whorl and umbilicus shape (+).

- Variation in shell size; longer in length with narrower width makes a slender shape shell (+) and shorter wider shell (-).

- Difference in spire-body whorl length aspect; higher spire - longer body whorl (+), and shorter spire - shorter body whorl (-).

- Difference in LM 17 and 18 making a pronounce body whorl and umbilicus shape (+).

- Difference in aperture outer margin shape; concave (-) and more elongated (+).

- Variation in spire orientation; leaning to the left (-), to the right (+).

4 - Difference in aperture outer margin shape; elongated lower margin (+) and rounder or concave margin (-).

- Difference in LM 17 and 18 giving a pronounce body whorl shape.

- Variation in spire orientation; leaning to the left(-), to the right (+).

5 - Difference in aperture outer margin shape; elongated margin $(+)$ and rounder margin (-).

RW Lanao del Norte

- Variation in spire-body whorl length aspect; longer spire-shorter body whorl length $(+)$ and shorter spire-longer body whorl length $(-)$

- Variation in aperture length-width; bigger aperture opening in (-).

$2 \quad$ - Variation in shell width, rounder body with wider width (+) and slender body shape (-).

- Difference in the aperture outer margin shape; wider in the lower portion $(+)$ and wider in the lower part (-) of the margin.

- Variation in the aperture length-width aspect; shorter length - wider opening making a round looking aperture shape (+) and longer

$3 \quad$ - narrower opening making a slender looking aperture (-).

- Slight difference in the shell width, wider shell in (+).

- Variation in shell orientation; leaning to the left(+) \& to the right (-).

$4 \quad$ - Difference in LM17 and 18 ; pronounce body whorl shape $(+)$.

RW Lanao del Sur

- Variation in shell shape; slender (-) and rounder (+).

1 - Difference in spire-body whorl length aspect; longer spire - shorter body whorl (-) and shorter spire - longer body whorl (+).

- Difference in aperture size; bigger aperture opening in (+) RW.

$2 \quad$ - Variation in shell shape (inverse of RW1); slender shaped (+) and rounder shaped (-).

3 - Variation shell orientation; leaning to the left(-) and to the right (+).

- Difference in spire length; longer spire in (+) RW.

$4 \quad$ - Variation shell orientation; leaning to the left(-) and to the right $(+)$.

- Difference in spire length; longer spire in (-) RW.

RW Misamis Oriental

- Variation in spire-body whorl length aspect; longer spire - short body whorl (+) and shorter spire - long body whorl (-).

1 - Difference in shell width; wider body in (+) RW.

- Difference in aperture size; bigger aperture in $(+)$.

- Variation in shell shape; slender shaped (-) and rounder shaped (+). 


\begin{tabular}{|c|c|}
\hline 3 & $\begin{array}{l}\text { - Difference in shell width; wider shell in (+) RW. } \\
\text { - Difference in aperture shape; slender aperture with narrow width (-) and rounder aperture with wider width }(+) . \\
\text { - Variation in spire-body whorl length aspect; longer spire - short body whorl (+) and shorter spire - long body whorl length (-). } \\
\text { - Difference in aperture length-width aspect; longer narrower aperture (-) and shorter wider aperture size (+). } \\
\text { - Difference in LM } 17 \text { and } 18 \text { giving a pronounce body whorl shape. }\end{array}$ \\
\hline RW & South Cotabato \\
\hline 1 & $\begin{array}{l}\text { - Variation in spire-body whorl length aspect; longer spire - short body whorl (-) and shorter spire - long body whorl length }(+) \text {. } \\
\text { - Variation in aperture size; longer and wider aperture in }(+) \text { RW. }\end{array}$ \\
\hline 2 & $\begin{array}{l}\text { - Variation in aperture outer margin shape; wider aperture width with larger upper part of the margin }(-) \text { and longer narrow aperture } \\
\text { with elongated lower margin }(+) \text {. }\end{array}$ \\
\hline 3 & $\begin{array}{l}\text { - Variation in shell width; wider shell in (-) RW. } \\
\text { - Variation in aperture outer margin shape; wider more concave aperture margin (+) and elongated on the lower aperture margin (-). } \\
\text { - Difference in LM 3, pronounce inner aperture margin outline (-). }\end{array}$ \\
\hline 4 & $\begin{array}{l}\text { - Variation in the shell width; wider shell in (+) RW. } \\
\text { - Variation in the aperture margin; concave lower margin (+) and elongated margin (-). } \\
\text { - Difference in LM } 5 \text { and } 6 \text { giving a concave inner aperture margin (-) and convex inner margin }(+) .\end{array}$ \\
\hline 5 & $\begin{array}{l}\text { - Variation in the spire orientation; leaning to the left (-)or to the right } \\
\text { - Slight difference in aperture size; larger aperture opening in the (-). }\end{array}$ \\
\hline RW & Zamboanga Sibugay \\
\hline 1 & $\begin{array}{l}\text { - Variation in shell shape; wider shell in (+) RW. } \\
\text { - Variation in spire-body whorl length aspect; longer spire - short body whorl (-) and shorter spire - long body whorl length (+). } \\
\text { - Difference in aperture size; bigger aperture in (+) RW. }\end{array}$ \\
\hline 2 & $\begin{array}{l}\text { - Variation in shell width; bigger wider shell in (+) RW. } \\
\text { - Difference in aperture length-width aspect; longer length and smaller width aperture (-), and shorter length wider aperture (+). }\end{array}$ \\
\hline 3 & $\begin{array}{l}\text { - Difference in aperture length-width aspect; longer length and smaller width aperture (+), and shorter length wider aperture (-). } \\
\text { - Difference in LM } 17 \text { giving a pronounce body whorl shape (-). }\end{array}$ \\
\hline 4 & - Variation in the shell orientation; leaning to the left $(+)$ and leaning towards the right (-). \\
\hline
\end{tabular}

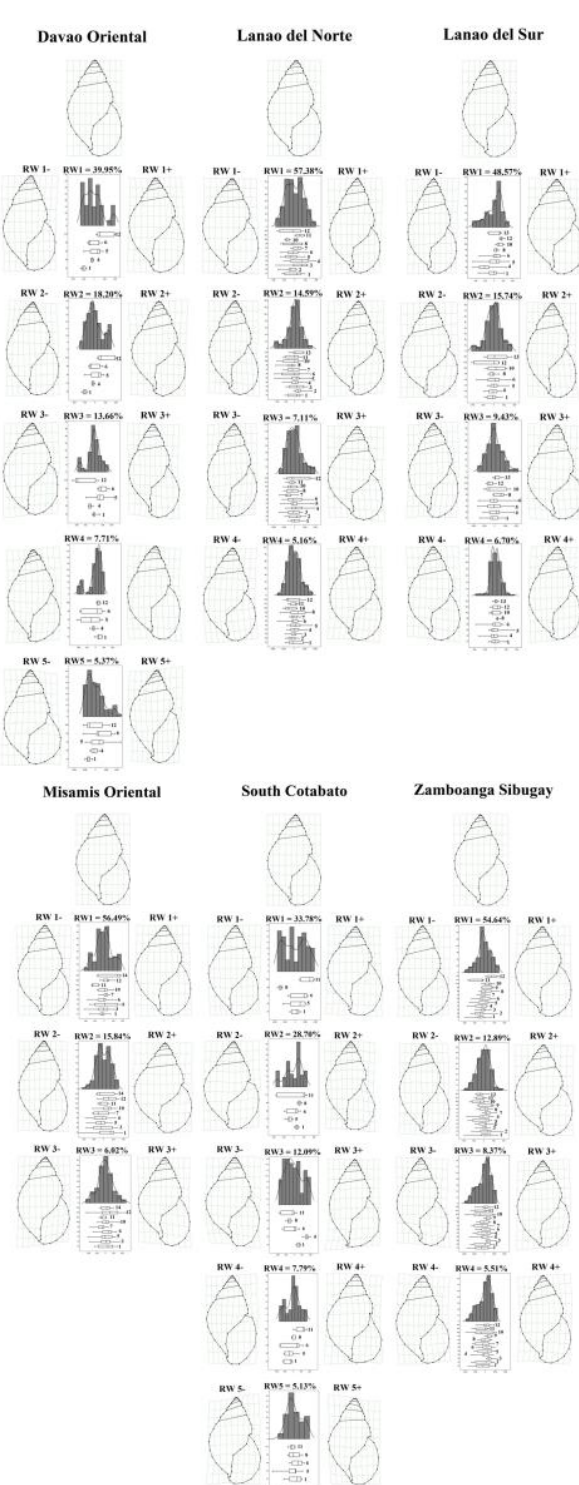

Fig. 3. Summary of the landmark based geometric morphometric analysis showing the consensus morphology (uppermost pannel) and the variation in shape of the shells of Achatina fulica from different geographical locations explained by each of the significant relative warps.

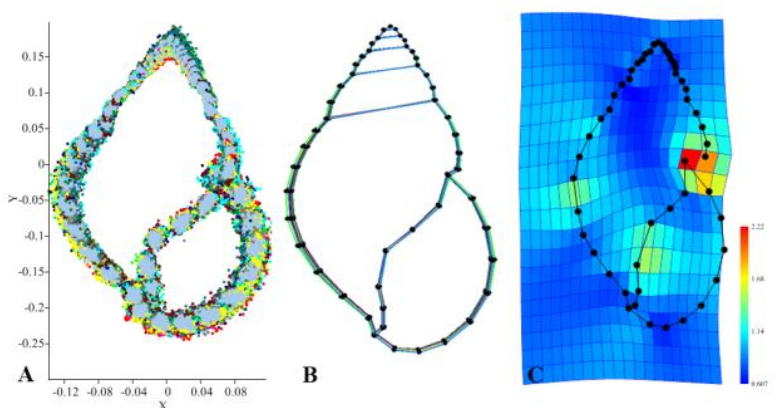

Fig. 4. XY graph of the landmark points (A), superimposition of the consensus $(\mathbf{B})$, and expansion map $(\mathbf{C})$ of the mean shape of A. fulica from the different geographical locations after generalized Procrustes analysis Legend: Cagayan (black), Pangasinan (red), Quezon (blue), Rizal (pink), Bohol (green), Southern Leyte (violet), Compostela Valley (yellow green), Davao del Norte (navy blue), Davao del Sur (neon blue), Davao Oriental (brown), Lanao del Norte (maroon), Lanao del Sur (blue green), Misamis Oriental (yellow), South Cotabato (gray), and Zamboanga Sibugay (sky blue); for expansion map: red to yellow - expansion, green to blue compression.

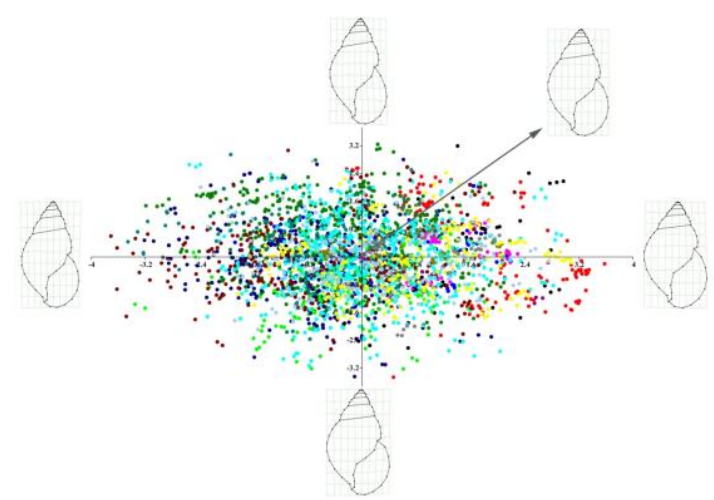

Fig. 5. CVA scatter plot showing the distribution of shell shapes of different patterns of samples from the different provinces of the Philippines based on landmark geometric morphometric analysis with corresponding shapes of each axis and the mean shape indicated by the arrow. Results of MANOVA test for significant variation in the shell shape: Wilk's Lambda $=\mathbf{0 . 6 7 7 7}$, df1 $1=28, d f 2=6864, F=52.46$, and $p($ same $)=2.68^{-263}$. Legend $:$ Cagayan (black), Pangasinan (red), Quezon (blue), Rizal (pink), Bohol (green), Southern Leyte (violet), Compostela Valley (yellow green), Davao del Norte (navy blue), Davao del Sur (neon blue), Davao Oriental (brown), Lanao del Norte (maroon), Lanao del Sur (blue green), Misamis Oriental (yellow), South Cotabato (gray), and Zamboanga Sibugay (sky blue). 
Fig. 4 shows the XY graph of the landmarks point, the superimpositions of mean consensus of each snail populations, and the expansion map plotted after general Procrustes analysis. Results showed that there were no direct observable morphological differences on the mean shapes of geographically isolated populations other than the compression of the body whorl and spire (concentrated on the lower and uppermost part of the shell, respectively), moderate expansion on the mid-body whorl left margin and aperture inner margin, and high expansion rate on the uppermost margin of the aperture where the aperture and the first spire suture meet. The expansion on the meeting point of the aperture and first suture corresponded to the biology of formation of the spire or simply the growth of the snail.

TABLE II: RESUlt OF KRUSKAL-WALLIS TEST ON SHELL SHAPE OF DIFFERENT BANDING PATTERN ON DIFFERENT GEOGRAPHICAL LOCATIONS BASED ON THE FIRST AND SECOND RELATIVE WARP SCORES. MANN-WHITNEY PAIRWISE COMPARISON (BONFERRONI CORRECTED) OF THE SHELl SHAPE BOLD NUMBERS INDICATE SIGNIFICANT DIFFERENCE (0.05 LEVEL OF SIGNIFICANCE)

\begin{tabular}{|c|c|c|c|c|c|}
\hline \multirow{2}{*}{ Location } & \multicolumn{5}{|c|}{ Location } \\
\hline & A & B & $\mathrm{C}$ & $\mathrm{D}$ & E \\
\hline A & - & & & & \\
\hline B & $2.273^{-03}$ & - & & & \\
\hline $\mathrm{C}$ & $1.161^{-02}$ & $7.64^{-17}$ & - & & \\
\hline D & 1 & 0.1274 & $9.01^{-10}$ & - & \\
\hline E & $1.05^{-12}$ & $8.21^{-43}$ & $6.34^{-08}$ & $4.58^{-29}$ & - \\
\hline $\mathrm{F}$ & 1 & 0.1041 & 1 & 0.8265 & $1.586^{-3}$ \\
\hline G & $1.13^{-09}$ & $9.50^{-32}$ & $7.04^{-05}$ & $4.35^{-23}$ & 1 \\
\hline $\mathrm{H}$ & $4.70^{-25}$ & $6.34^{-61}$ & $2.19^{-30}$ & $8.18^{-50}$ & $2.96^{-14}$ \\
\hline I & $1.52^{-07}$ & $1.63^{-34}$ & $3.147^{-02}$ & $8.32^{-22}$ & $\begin{array}{c}02.89^{-0} \\
4\end{array}$ \\
\hline $\mathrm{J}$ & 0.4451 & $7.75^{-09}$ & 1 & $1.53^{-05}$ & $\underset{4}{02.47^{-0}}$ \\
\hline K & $1.59^{-11}$ & $4.34^{-36}$ & $2.38^{-08}$ & $6.25^{-24}$ & 1 \\
\hline $\mathrm{L}$ & $1.38^{-17}$ & $1.46^{-41}$ & $3.61^{-17}$ & $3.07^{-37}$ & $3.79^{-04}$ \\
\hline M & 0.8294 & $1.74^{-13}$ & 1 & $6.98^{-05}$ & $2.11^{-15}$ \\
\hline $\mathrm{N}$ & 1 & 0.0901 & $1.586^{-02}$ & 1 & $6.48^{-12}$ \\
\hline \multirow[t]{2}{*}{$\mathrm{O}$} & $4.07^{-06}$ & $7.02^{-25}$ & 0.1308 & $7.28^{-17}$ & 0.9491 \\
\hline & $\mathrm{F}$ & $\mathrm{G}$ & $\mathrm{H}$ & I & $\mathrm{J}$ \\
\hline F & - & & & & \\
\hline G & $1.332^{-02}$ & - & & & \\
\hline $\mathrm{H}$ & $3.96^{-11}$ & $7.83^{-11}$ & - & & \\
\hline I & $\begin{array}{c}0.0824 \\
6\end{array}$ & 0.2798 & $3.26^{-37}$ & - & \\
\hline $\mathrm{J}$ & 1 & ${ }_{3}^{1.582^{-0}}$ & $4.67^{-18}$ & 0.4985 & - \\
\hline K & $4.92^{-04}$ & 1 & $1.11^{-04}$ & $7.98^{-06}$ & $2.68^{-05}$ \\
\hline $\mathrm{L}$ & $4.91^{-09}$ & $\begin{array}{c}4.502^{-0} \\
3\end{array}$ & 1 & $7.04^{-13}$ & $1.36^{-11}$ \\
\hline M & 1 & $1.29^{-08}$ & $3.37^{-41}$ & $3.01^{-06}$ & 1 \\
\hline $\mathrm{N}$ & 1 & $1.42^{-10}$ & $4.20^{-25}$ & $5.34^{-08}$ & 0.0764 \\
\hline \multirow[t]{2}{*}{$\mathrm{O}$} & $3.419^{-02}$ & 1 & $9.49^{-18}$ & 1 & 0.2403 \\
\hline & $\mathrm{K}$ & $\mathrm{L}$ & $\mathrm{M}$ & $\mathrm{N}$ & $\mathrm{O}$ \\
\hline K & - & & & & \\
\hline $\mathrm{L}$ & 1 & - & & & \\
\hline M & $1.22^{-13}$ & $2.55^{-20}$ & - & & \\
\hline $\mathrm{N}$ & $3.17^{-11}$ & $4.44^{-20}$ & 0.7606 & - & \\
\hline $\mathrm{O}$ & 0.0283 & $8.69^{-07}$ & $7.6^{-04}$ & $1.80^{-07}$ & - \\
\hline
\end{tabular}

Legend : Cagayan (A), Pangasinan (B), Quezon (C), Rizal (D), Bohol (E), Southern Leyte (F), Compostela Valley (G), Davao del Norte (H), Davao del Sur (I), Davao Oriental (J), Lanao del Norte (K), Lanao del Sur (L), Misamis Oriental (M), South Cotabato (N), and Zamboanga Sibugay (O).

The CVA scatter plot (Fig. 5), analysis across geographically isolated populations based on the most important warp scores, reveals an overlapping of shell shaped distribution suggesting a high intrapopulation variation. Pangasinan population was seen with data set distribution only on the first and forth quadrant of the graph. However, data of shell shape still overlapped with the other populations. MANOVA results were significant for the correlation of shell shape and geographical location. It was also important to consider the result of the Kruskal-Wallis test ( $\mathrm{p}=1.932-115$ $<0.05$ ) based on the first and second relative warp scores. Finding showed that there was a significant difference between the medians of at least two populations. The result of the Bonferroni corrected Mann-Whitney pairwise comparison of the most significant warp scores (first and second) of the shell shape of all geographically isolated populations.

The general clustering pattern of the variation contained in the shell shape data of geographically isolated populations of Achatina fulica was illustrated by a single tree of Cluster analysis, resulting to two significant groups (Fig. 6). The first significant branch is comprised of the shell populations from Quezon, Bohol, Lanao del Norte, Zamboanga Sibugay, Davao del Norte, and Lanao del Sur were shown to have wider distance of variation. The second group was observed with shorter distance from each other; this connotes that populations were not significantly different from each other. Shell population from Quezon, Luzon appeared to be the most significantly different in terms of shell shape. No clustering of shell shapes by major islands of the Philippines was seen. No clustering of shell shapes by neighboring regions was also observed. This distribution suggested the invasiveness of $A$. fulica.

In the study on shell banding pattern populations, higher intrapopulation variation rather than interpopulation was observed [13]. Also the current study on the geographically isolated populations of shells with different banding patterns revealed higher intrapopulational variation than interpopulation variation. Results showed a vast array of possible multitude of factors affecting the configuration of $A$. fulica shell shape in natural populations. A study stated that there was still an unclear factor on the driving morphometric shape variation among littorinid gastropods [25]. The same study suggested that phenotypic difference was due to the snail's ability to adapt to wide range of microhabitat characteristics. In the study on the littorine snail Bembicium vittatum [26] and on the phenotypic evolution of Candicula unifasciata [11], it was found out that shell shape correlated with physical habitat conditions. Furthermore, the A. fulica is a nocturnal snail and is moisture dependent, being more active in high humidity conditions [6], [27].

Other studies on conchological variation stated that shell shape showed a strong relation of the preferred habitat [16], [28], [29]. In the case of A. fulica, few studies reported that though the snail species exhibit wide environmental tolerance, the giant African snail preferred warm habitats [1], [2], [6]. In the study of [6], results of simple regression indicated that humidity had a significant influence on A. fulica total length and weight. Reference [11] stated that a smaller aperture is an adaptation minimizing the area of exposed surface, thus having the advantage by minimizing the loss of humidity under water stress conditions. In addition, it was reported that smaller shells on snail species were also explained as potential adaptation of the area volume ratio to reduce the loss of water in dry area with low rainfall. Regarding the distribution of A. fulica, [2] identified temperature seasonality 
and temperature of coldest quarter are the two variables having the most important effect on the possible dispersal of the species of land snail. Ref. [6] considered temperature range as the main variable that influenced the condition factor (shell length-width relationship). Moreover, a study found that A. fulica becomes active when humidity rises over $50 \%$ and that means temperature and temperature range would affect the snail body weight [30]; and severe temperature change and prolonged dry periods could encourage the aestivation of the giant land snail [6], [31], [32]. The aestivation stage may also promote physiological changes in A. fulica and would affect the snail's development [33]. Another factor behind morphology is the possible adaptation of the snail to areas with varied amount of substrate [16], especially the availability of soil calcium [34], which could affect the shell size and structure. On the other hand, the researchers of the present study were aware of the uneven sample size across populations, yet, the issue was compensated by creating triplicates and pooling data. The imbalance of samples was presumably reflecting the patchy distribution of the snails rather than the uneven collecting effort [16].

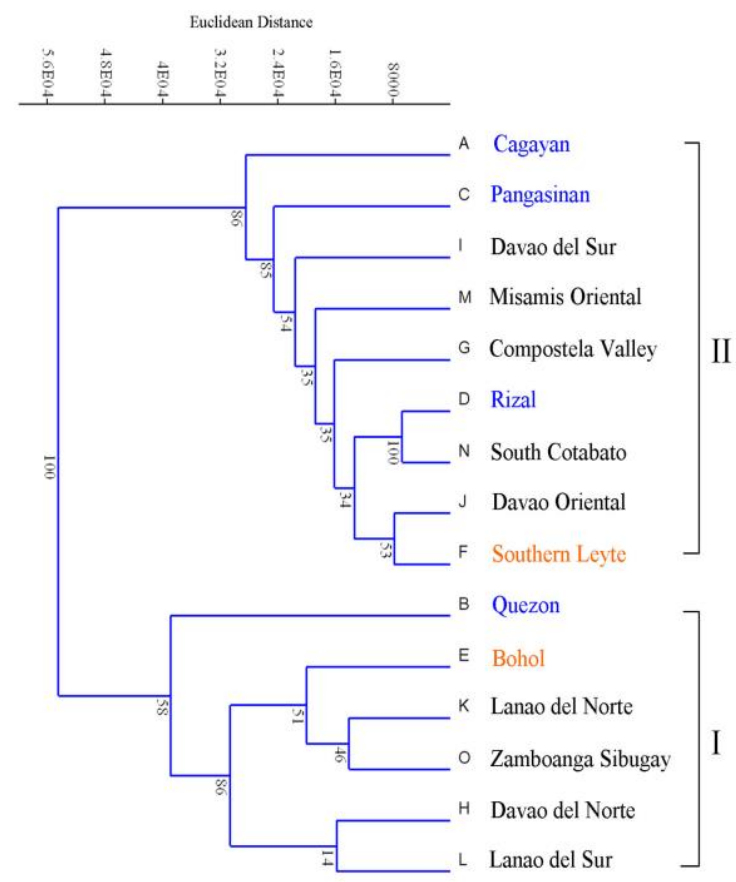

Fig. 6. Hierarachical tree generated by Cluster Analysis of the centroid size showing the degree of similarity of shell morphology of A. fulica from different geographical locations in the Philippines. Legend: Blue (Luzon regions), Red (Visayas regions), and Black (Mindanao regions).

\section{CONCLUSION}

It has been demonstrated that there was a significant difference in shells of snails with different banding patterns across population of geographically isolated Achatina fulica. The overlapping of data distribution and short distance variation suggest a higher intrapopulation variation rather than interpopulation aspect. A question will always arise as to what causes the observed variations. Phenotypic plasticity, common in land snails, could be another explication for the observed intrapopulation conchological variations. Differentiation could also be due to endogenous (genetic and physiology) and exogenous (biotic and abiotic interaction) factors.

For further study, it is of interest to consider the relationship of the conchological variation to microhabitats to further understand the biology of the invasive giant land snail.

\section{ACKNOWLEDGMENT}

The senior author would like to acknowledge the Department of Science and Technology - Accelerated Science and Technology Human Resource Development Program (DOST-ASTHRDP) for the scholarship grant. Acknowledgment is also extended to Muhmin Michael Manting for the technical assistance.

\section{REFERENCES}

[1] S. K. Raut and G. M. Barker, "A. fulica Bowdich and Other Achatinidaeas Pests in Tropical Agriculture," in G. M. Barker ed., Molluscs as Crop Pests, pp. 55-114, Hamilton: CABI Publishing, 2002.

[2] R. E. Vogler, A. A. Beltramino, M. M. Sede, D. E. Gutiérrez Gregoric, V. Núñez, and A. Rumi, "The giant African snail, Achatina fulica (Gastropoda: Achatinidae): Using bioclimatic models to identify South American areas susceptible to invasion,” Amer. Malac. Bull., vol. 31, issue 1, pp. 39-50, Feb. 2013.

[3] Invasive Species Specialist Group. (2012) .Global Invasive Species Database. A. fulica. [Online]. Available: http://www.issg.org/database/species/ecology.asp?si=64\&fr=1\&sts=s ss\&lang $=\mathrm{EN}$

[4] R. C. Venette and M. Larson. "Mini Risk Assessment Giant African Snail, A. fulica Bowdich (Gastropoda: Achatinidae)," Department of Entomology, University of Minnesota, Sept. 29, 2004.

[5] T. Pattamarnon, "Shell morphological differences and genetic variation of the giant African snail A. fulica Bowdich in Thailand," Ph.D. dissertation, Suranaree University of Technology, 2004.

[6] F. S. Albuquerque, M. C. Peso-Aguiar, M. J. T. Assunção-Albuquerque, and L. Gálvez, "Do climate variables and human density affect Achatina fulica (Bowditch) (Gastropoda: Pulmonata) shell length, total weight and condition factor?" Braz. J. Biol., vol. 69, issue 3, pp. 879-885, Aug. 2009.

[7] M. Correoso and M. Coello, "Modelación y distribución de Lissachatina fulica(Gastropoda: Achatinidae) en Ecuador, Potenciales impactos ambientales y sanitarios," Revista Geoespacial, vol. 6, pp 79-90, 2009.

[8] F. J. Borrero, A. S. H. Breure, C. Christensen, M. Correoso, and V. M Ávila, "Into the Andes: Three new introductions of Lissachatina fulica (Gastropoda, Achatinidae) and its potential distribution in South America," Tentacle, vo. 17, pp. 6-8, Jan. 2009.

[9] E. Colley, “Medidas de controle de Achatina fulica," in M. L. Fischer and L. C.M. Costa, eds., O Caramujo Gigante Africano Achatina fulica no, Brasil, Editora Universitária Champagnat, Curitiba, Brazil, pp. 203-230, 2010.

[10] D. E. G. Gregoric, V. Núñez, R. E. Vogler, and A. Rumi, "Invasion of the Argentinean Paranense Rainforest by the Giant African Snail Achatina fulica," American Malacological Bulletin, vol. 29, pp. 135-137, Nov. 2011.

[11] M. Pfenninger, and F. MagniN, "Phenotypic evolution and hidden speciation in Candidula unifasciata ssp. (Helicellinae, Gastropoda) inferred by 16 s variation and quantitative shell traits," Mol Ecol., vol. 10 , issue 10 , pp. 2541-54, Oct. 2001

[12] C. Graeff-Teixeira, "Epidemiology of Abdominal Angiostrongylosis in Southern Brazil," Parasitology International, vol. 47, no. 3, pp. 23-48, Aug. 1998.

[13] J. M. M. Sobrepeña and C. G. Demayo, "Banding pattern and shape morphology variations on shells of Achatina fulica (Bowdich 1822) from the Philippines," Annals of Biological Research, vol. 5, issue 1, pp. 64-79, Jan. 2014.

[14] L. Madec, A. Bellido, and A. Guiller, "Shell shape of the land snail Cornu aspersum in North Africa: unexpected evidence of a phylogeographical splitting," Heredity, vol. 91, pp. 224-231, Sept. 2003.

[15] M. A. J. Torres, R. C. Joshi, L. S. Sebastian, and C. G. Demayo, "Geographic phenetic variation in the golden apple snail, Pomacea 
canaliculata (Ampullariidae) based on geometric approaches to morphometrics," AES Bioflux, vol. 3, pp. 243-258, Sept. 2011.

[16] M. Haase and B. Misof, "Dynamic gastropods: stable shell polymorphism despite gene flow in the land snail Arianto arbustorum," J. Zool Syst Evol Res, vol 47, issue 2, pp. 105-114, Dec. 2008.

[17] V. G. D. Rosa, M. A. J. Torres, and C. G. Demayo, "Geometric Morphometric Tools in the Analysis of Shell Shape of Twelve Local Populations of the Invasive Snail Achatina Fulica Bowdich from the Philippines," International Conference on Environmental Engineering and Applications, Singapore, Sept. 10-12, 2010.

[18] P. Morais, M. M. Rufino, J. Reis, E. Dias, and R. Sousa, "Assessing the morphological variability of Unio delphinus spengler, 1783 (Bivalvia: Unionidae) using geometric morphometry," Journal of Molluscan Studies, pp. 1-7, Oct. 2013.

[19] F. J. Rholf, "tpsDig program," Ecology and Evolution, SUNY at Stony Brook, 2008

[20] F. J. Rohlf, "Relative Warps version 1.46," Ecology and Evolution, SUNY at Stony Brook, 2008

[21] F. J. Rohlf, "tps Utility program version 1.44," Ecology and Evolution, SUNY at Stony Brook, 2009

[22] Ø. Hammer, D. A. T. Harper, and P. D. Ryan, "PAST: Paleontological Statictics software package for education and data analysis," Paleontologia Electronica, vol. 4, issue 1, June 2001.

[23] O. S. Anies, M. A. Torres, M. M. Manting, and C. G. Demayo, "Landmark-Based Geometric Morphometrics in Describing Facial Shape of Sama-Banguingui Tribe in the Philippines," Journal of Medical and Bioengineering, vol. 2, no. 2, pp. 131-136, June 2013.

[24] D. E. Slice, F. L. Bookstein, L. F. Marcus, and F. J. Rohlf. (1996). A Glossary of geometric morphometrics. [Online]. Available: http://life.bio.sunysb.edu/morph,

[25] H. Queiroga, R. Costa, N. Leonardo, D. Soares, and D. F. R. Cleary, "Morphometric variation in two intertidal littorinid gastropods," Contributions to Zoology, vol. 80, issue 3, pp. 201-211, Sept. 2011.

[26] M. S Johnson and R. Black R, "Associations with habitat versus geographic cohesiveness: size and shape of Bembicium vittatum Philippi (Gastropoda: Littorinidae) in the Houtman Abrolhos Islands," Biological Journal of the Linnean Society, vol. 71, pp. 563-580, Nov. 2000.

[27] S. G. Raut and K. C. Goshe, "Pestiferous land snails of India," Calcuta: Bani Press, p. 151, 1984

[28] A. J. Cain and R. H. Cowie, "Activity of different species of land snail on surfaces of different inclinations," J Conch., vol. 29, pp. 267-272, 1978.
[29] L. M. Cook, and W. N. Jaffar, "Spire index and preferred surface orientation in some land snails," Biol J Linn Soc, vol. 21, pp. 307-313, 1984.

[30] N. Takeda and T. Osaki, "Introduction of locomotor behaviuor in giant African Snail Achatina fulica," Comparative Biochemistry and Physiology, vol. 83, no. 1, pp 77-82, 1986.

[31] H. Suzuki and K. T. Yasuda, "Studies on Ecology and control of the giant African Snail, Achatina fulica Bowdich, in Okinawa Islands," Bulletin of the Okinawa Agricultural Experiment Station, vol. 8, pp. 43-50, 1983

[32] K. Takeuchi, S. Koyano, and K. Numazawa, "Occurrence of the Giant African Snail in Ogasawara Islands, Japan," Micronesica, no. 3, pp. 109-116, 1991.

[33] G. K. Vinic, V. K. Unnithan, and V. V. Sugunan, Farming of the Giant African Snail, Achatina fulica, India: Central Inland Capture Fisheries Research Institute, no. 56, pp. 1-24, 1998.

[34] M. Charrier, A. Marie, D. Guillaume, L. Bédoue, J. Le Lannic, C. Roiland, S. Berland, J. S. Pierre, M. Le Floch, Y. Frenot, and M. Lebouvier, "Soil Calcium Availability Influences Shell Ecophenotype Formation in the Sub-Antarctic Land Snail, Notodiscus hookeri," PLoS ONE, vol. 8, no. 12, p. e84527, doi:10.1371/journal.pone.0084527, Dec. 2013.

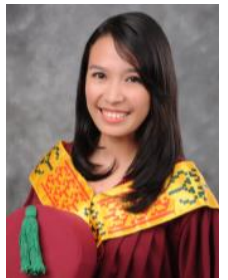

Jade Marie M. Sobrepeña is currently pursuing her master of science in biology degree at the MSU-Iligan Institute of Technology, Iligan City, Philippines.

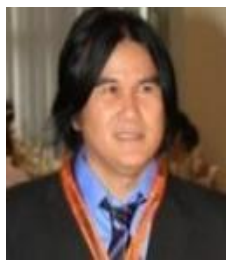

Cesar G. Demayo is the current chairman and professor of the Department of Biological Sciences, College of Science and Mathematics, MSU-Iligan Institute of Technology, Iliga City, Philippines. His researches include environmental toxicology, biodiversity and genetics. He is an active member of the Philippine Society for the Study of Nature and the Pest Management Council of the Philippines. 